BACD welcomes new President

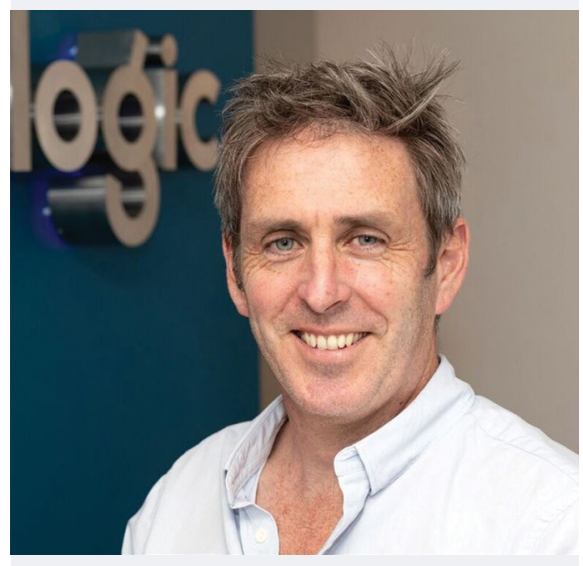

Chris McConnell took up the gauntlet as new President of the British Academy of Cosmetic Dentistry (BACD) in November 2021.

Chris is a general dentist with a special interest in cosmetic and sedation dentistry and is principal of St Piran Dental based in Perranporth, Cornwall.

Chris said that he is looking forward to building upon what is already a widely respected organisation: 'The BACD is very well recognised across the world, known for bringing amazing speakers to conferences and promoting the importance of going back to basics in terms of clinical skills, education and networking.

'I would like to see the BACD promoted more in the public arena. I believe it is important to engage with the general population and make them aware of how to check a cosmetic dentist's credentials before proceeding with treatment.

'Our aim is to carry on supporting members during and after COVID, giving ever-greater value for BACD membership.

'We are restructuring the $\mathrm{BACD}$ educational programme to offer even more hands-on opportunities and some great new events for members. We have a fantastic lecture in the memory of Anoop Maini in June and the first ever BACD residential conference in November 2022 with Frank Spear headlining on Friday - a rockstar of US dentistry who rarely lectures in Europe, so it's a massive deal to see him this side of the pond!'

\title{
New era for MIH research and patient management
}

A new research initiative is being established to take the dental profession's understanding of molar incisor hypomineralisation (MIH) and its impact on patients into a new era. Led by Greig Taylor (pictured), a member of the British Society of Paediatric Dentistry (BSPD) and Chairman of CONNECT, a research collaborative for trainees, the initiative will bring together academics keen to share knowledge as well as to gain the input of children and young people in optimum management of the condition.

A common childhood condition, $\mathrm{MIH}$ causes weakened tooth enamel, usually in one or more of the first permanent molars, which are more prone to dental decay as a result; incisor teeth can be affected too.

Until the turn of this century, teeth with weakened enamel might have been referred to as 'cheesy molars' due to their pitted appearance. A seminal paper ${ }^{1}$ published exactly 20 years ago, however, established the use of the classification 'molar incisor hypomineralisation'.

There have been numerous studies of $\mathrm{MIH}$ in recent years including a paper ${ }^{2}$ in 2017 which showed that the global burden is high. Evidence from a paper ${ }^{3}$ in the International Journal of Paediatric Dentistry (based on 70 studies) suggests that the prevalence in children is roughly $14 \%$.

Another important development from the last two decades is the development of BSPD's position statement, ${ }^{4}$ launched in January 2020, ensuring that the condition is widely taught and recognised. According to the statement, about one million children in the UK have teeth that are affected by MIH, and in most cases, the treatment can and should be managed in primary care. Only the most severe cases or those which require multidisciplinary management should be referred into secondary care.

The European Academy of Paediatric Dentistry undertook a systematic review to understand worldwide trends in the scientific evidence around MIH and gaps in knowledge with a view to guiding future research on the topic. Its updated policy document ${ }^{5}$ to which BSPD's Mr Taylor, Dr Cheryl Somani and Professor Ferranti Wong contributed, has just been published.

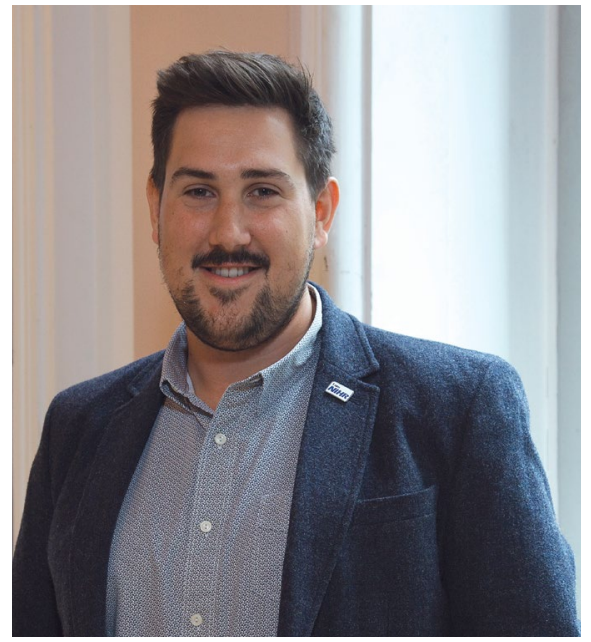

Mr Taylor said the knowledge gap that has been identified is around a shortage of clinical studies on treatment, mainly extractions, and on the patient's quality of life. He added: 'There is definitely a genetic component to MIH but we still don't fully understand what causes it. Our best course of action is to focus on prevention and early identification.

He is now in discussion with other BSPD academics interested in working together in the UK and internationally to develop the evidence base further. Professor Claire Stevens, spokesperson for BSPD, said: 'We see high numbers of children who have $\mathrm{MIH}$ and need treatment. I am delighted that Greig and others are going to be working together to fill the knowledge gap on $\mathrm{MIH}$ and to ensure that the advice and resources that we develop for our young patients are co-designed with them'

\section{References}

1. Weerheijm K L, Jalevik B, Alaluusua S. Molar-incisor hypomineralisation. Caries Res 2001; 35: 390-391.

2. Schwendicke F, Elhennawy K, Reda S, Bekes K Manton D J, Krois J. Global burden of molar incisor hypomineralization. J Dent 2018; 68: 10-18.

3. Zhao D, Dong B, Yu D, Ren Q, Sun Y. The prevalence of molar incisor hypomineralization: evidence from 70 studies. Int J Paediatr Dent 2018; 28: 170-179.

4. British Society of Paediatric Dentistry. Molar Incisor Hypomineralisation (MIH). A BSPD position paper on the dental condition affecting 1m UK children. 2020. Available at: https://www.bspd.co.uk/Portals/0/ MIH\%20statement\%20final\%20Jan\%202020.pdf (accessed November 2021).

5. Lygidakis N A, Garot E, Somani C, Taylor G D, Rouas $P$, Wong $F S$ L. Best clinical practice guidance for clinicians dealing with children presenting with molar-incisor-hypomineralisation (MIH): an updated European Academy of Paediatric Dentistry policy document. Eur Arch Paediatr Dent 2021; doi: 10.1007/ s40368-021-00668-5. 